\title{
Hyperthermia in rheumatic diseases. A promising approach?
}

\section{Krzysztof Jeziorski}

Department of Gerontology, Public Health, and Didactics, National Institute of Geriatrics, Rheumatology, and Rehabilitation, Warsaw, Poland

Maria Sklodowska-Curie Memorial Cancer Centre and Institute of Oncology, Warsaw, Poland

\begin{abstract}
Hyperthermia is a method applied in the treatment of many diseases, including rheumatic diseases. There are relatively few reports concerning the role of that method in the treatment of these diseases, and most studies have not been randomised. Hyperthermia includes directed application of thermal energy. The aim of that therapy is to overcome the body's natural thermoregulation mechanism through application of external heat sources such as electromagnetic radiation of various frequencies, or ultrasound. Usually, temperatures are used within the $38.5-43^{\circ}$ range. Hyperthermia can be applied as topical, regional, or systemic treatment (the latter is called hyperthermia of the whole body). In rheumatology, mainly the effect of hyperthermia on the immune system of the body is used. That effect depends on the type of hyperthermia and temperatures applied. Best documented are the effects of hyperthermia in fibromyalgia and ankylosing spondylitis.
\end{abstract}

Key words: hyperthermia, rheumatology, ankylosing spondylitis, fibromyalgia.

\section{Introduction}

A history of application of hyperthermia in medicine, especially in rheumatic diseases, dates back to the beginning of the $20^{\text {th }}$ century. As early as in 1929 Neyman and Osborne described the employment of high-frequency currents in the production of fever [1]. The publication of this paper led to the therapeutic use of this method in various chronic diseases. Six years later Short and Bauer described the results in 25 cases of rheumatoid arthritis treated with fever produced by general diathermy [2].

Hyperthermia is a method used in the treatment of many diseases, particularly malignancies. In oncology, it is regarded as adjunctive therapy and is used in combination with radiotherapy, chemotherapy, or chemoradiotherapy. While in oncology many new reports are published on the methods and role of hyperthermia in the combined treatment of tumours, relatively few reports can be found on the role of that method in the therapy of other conditions, particularly rheumatic diseases.

Hyperthermia includes directed application of thermal energy [3]. The aim of the therapy is to overcome the body's natural thermoregulation mechanism through application of external heat sources such as electromagnetic radiation of various frequencies, or ultrasound. Usually, temperatures are used within the $38.5-43^{\circ}$ range. Hyperthermia is called a non-ionising form of radiotherapy, which can increase the effectiveness of treatment of various diseases. Hyperthermia can be applied as topical (deep or superficial hyperthermia), regional, and systemic treatment (called hyperthermia of the whole body) [4]. Topical hyperthermia is directly limited to the pathological lesion and includes the use of applicators on the body surface or inside body cavities or in tissues. Regional hyperthermia is applied usually in the therapy of malignant diseases involving a larger body region, e.g. the limbs or body cavities. Therefore, it is also applied in the therapy of sarcomas or melanomas. It can also take the form of regional perfusion hyperthermia or intraperitoneal hyperthermia. While the aim of topical or regional hyperthermia includes selective heating of a given body region, systemic hyperthermia is a form of artificial fever, since the temperature elevation involves the patient's whole body.

\section{Address for correspondence:}

Krzysztof Jeziorski, Department of Gerontology, Public Health, and Didactics, National Institute of Geriatrics, Rheumatology and Rehabilitation, 1 Sparttańska St., 02-637 Warsaw, Poland, e-mail: krzysztof.jeziorski@wp.pl

Submitted: 17.07.2018; Accepted: 2.10.2018 
The biological-molecular foundations of the application of hyperthermia in rheumatic diseases, contrary to malignant diseases (changes in blood perfusion of a malignant tumour and its microenvironment, production of heat shock proteins, denaturation of the proteins contained in the cell cytoplasm and cell membranes, disturbance of the mechanisms of damaged DNA repair, changes of malignant cell shape and induction of apoptosis due to activation of procaspase-2 by hyperthermia leading to activation of many protein systems) include, in the first place, the effect exerted on the immune system through its modulation [5].

That effect is used in oncological hyperthermia, but in the therapy of rheumatic diseases, as opposed to that observed in oncology, it depends on the range of temperatures used and the type of hyperthermia applied (topical or systemic) [6]. The use of hyperthermia at temperatures exceeding $41^{\circ} \mathrm{C}$ leads to suppression of the immune system [7], while so-called mild topical hyperthermia (temperature below $41^{\circ} \mathrm{C}$ ) stimulates the immune system and leads to activation of two proinflammatory cytokines: interleukin 1 and interleukin 6, with a simultaneous decrease of the concentrations of two other cytokines: prostaglandin E2 and leukotriene B4, while so-called intensive topical hyperthermia (temperature above $41^{\circ} \mathrm{C}$ ) leads to suppression of the humoral and cell-mediated immune responses. A similar effect is observed in the case of intensive systemic hyperthermia. Experimental studies demonstrated reductions of the number of immune system cells in the lymph nodes, spleen, and thymus. Mild systemic hyperthermia induced an increase of immunity and synthesis of gamma interferon.

According to Schmidt [8], the systemic effect of hyperthermia causes activation of various functions of mononuclear cells, including increase in globulin synthesis and protection of WEHI-175 cells against apoptosis induced by TNF- $\alpha$. Furthermore, the beneficial actions of hyperthermia include an analgesic effect and reduction of skeletal muscle and tendon tonus. Besides that, compared with topical hyperthermia, systemic hyperthermia applied in rheumatic diseases penetrates deeper into soft tissues and joints, thus alleviating such signs as inflammation of tendon attachments, arthritis, and spondylitis [9-13].

Markovic [14] investigated in vitro the effect and mechanisms of short-term hyperthermia on a series of proinflammatory genes in type B-synoviocytes (fibroblast like synoviocytes - FLS). Exposure of FLS to elevated temperatures influenced the activities of some proinflammatory cytokines such as: IL-1 $\beta$, TNF- $\alpha$, IL-1 $\beta$ and IL-8 as well as COX-2 protein synthesis. This may explain the role of hyperthermia in the treatment of inflammation in rheumatoid arthritis (RA) [14].

Short-term hyperthermia prevents the activation of $N F-\kappa B$ and blocks the activation of MAPK p38. The effects of hyperthermia on $\mathrm{p} 38$ are independent of hyperthermia effects on NF-кB. This is demonstrated by the ability of short-term hyperthermia to prevent IL-1 $\beta$ induced activation of MAPK p38-dependent, but NF- $\mathrm{KB}$-independent, genes [15].

Hyperthermia exerts its effects also on blood cells. In a study by Huang et al. [16] exposure of peripheral blood mononuclear cells (PBMC) to mild hyperthermia between $39^{\circ} \mathrm{C}$ and $41^{\circ} \mathrm{C}$ for 90 minutes induced cell proliferation in a group of healthy blood donors, while hyperthermia at $42^{\circ} \mathrm{C}$ had no significant effect. Also, mitogen-induced PBMC proliferation and secretion of immunoglobulins of IgG, IgA, and IgM type were also significantly enhanced by mild hyperthermia, indicating B-cell activation [16]. Long-term hyperthermia may inhibit IL-1 $\beta$, IL-6, and TNF- $\alpha$ production in PBMC [17].

Also, hyperthermia increases significantly serum cortisol, plasma norepinephrine, and plasma epinephrine concentrations compared to controls. It is possible that the observed changes in the function of blood mononuclear cells may be induced by elevated levels of stress hormones [18]. Moreover, hyperthermia causes changes on the neuroendocrine level, such as a decrease of substance $P$, an increase of serum $\beta$-endorphins, an influence of immunocompetent cells of the skin (Langerhans cells), and activation of the cell's own repair mechanisms. Hyperthermia influences the activity of granulocytes by increasing their mobility, phagocytic and bactericidal properties, and enzymatic activity [19].

Although beneficial effects of hyperthermia in rheumatology have been reported, the methodological quality of studies is not sufficient. The majority of studies are non-randomised and include a small number of participating patients. However, hyperthermia is becoming one of most prospective methods owing to its low cost, convenience, and few side effects. Hyperthermia can alleviate patients' pain, selectively destroy proliferating cells, reduce the intensity of the inflammatory response, strengthen their muscles, relive muscle spasm, improve range of motion, and induce immunostimulation [20-22]. Experiments on animals showed that thermal measurements strongly correlate with arthritis activity and severity indices [23]. So, maintaining the temperature in a proper range may help in the recovery of different bones, especially knees, from arthritis.

The distribution of heat in the human knee was described by Xiao et al. [24]. Taking into account the anatomical structure of human knee, Xiao et al. developed a theoretical model for three-dimensional temperature 
fields of the human knee. The human knee includes: bone, cartilage, synovia, muscle, vessel, skin, and other tissues of different thermal properties. To simplify, there are three main types of heat transfer in the knee: conduction, convection, and radiation. Localised hyperthermia showed beneficial effects in patients with moderate osteoarthritis to reduce pain and to improve their physical function. The available publications show, however, that, similarly as in oncology, hyperthermia cannot replace the basic methods applied in the therapy of rheumatic diseases.

The role of hyperthermia has been best documented in the treatment of ankylosing spondylitis (AS) and fibromyalgia. In the study by Tarner et al. [6], systemic hyperthermia applied in patients with AS, compared with a group of healthy volunteers, caused a significant drop in the concentrations of cytokines: TNF- $\alpha$, IL- $1 \gamma$, and IL- 6 by $40-50 \%$ in the group of AS patients. In both groups nine sessions of hyperthermia were conducted at a temperature of $38.5^{\circ} \mathrm{C}$, and the determinations of cytokines were carried out 1, 6, and 24 hours after the beginning of the last hyperthermia session.

In the experimental studies on AS, systemic hyperthermia not only alleviated the pathological symptoms but also prevented further progression of the disease, which suggests that the main action of hyperthermia in rheumatic diseases is based on anti-inflammatory effects and it is not a heat stress effect. Moreover, the beneficial action of hyperthermia included an analgesic effect and reduction of the skeletal muscle and tendon tonus. The analgesic effect of hyperthermia in rheumatic diseases is particularly worth stressing, especially in patients with fibromyalgia and AS [25]. The analgesic effect of hyperthermia is explained based on two hypotheses: metabolic and neurological. According to the first hypothesis, hyperthermia causes an elimination of the inflammatory factors stimulating the nerve endings. On the other hand, according to the neurological hypothesis, hypothermia modulates the conduction in the nerve fibres. Furthermore, hyperthermia causes an increase of the concentration of circulating endorphins.

In a randomised trial in patients with fibromyalgia, assessing the effects of standard rehabilitation procedures compared with rehabilitation procedures combined with systemic hyperthermia, a better control of pain complaints was found in the group of patients treated with rehabilitation procedures and hyperthermia [26].

Application of mild whole-body hyperthermia in fibromyalgia resulted in significant reduction of pain immediately after the treatment, and after nine hyperthermia treatments during three weeks pain no longer reached its pre-treatment level [7]. Local heat applica- tion may be of significant benefit in inflammatory and noninflammatory rheumatic diseases. Mild hyperthermia has a significant analgesic effect in fibromyalgia. The therapeutic results depend on dosage, kind of application, and severity of inflammation. In very acute inflammation, heat treatment should be applied carefully because it may aggravate the inflammatory effect [7].

In the German study of Chrubasik et al. [27] evaluating two thermotherapeutic and two pharmacological anti-inflammatory/analgesic treatments (oral drug treatment, parenteral drug treatment, mud pack application, and hyperthermia) of skeletomuscular pain in a sample of about 1400 patients, the best results were observed when heat therapy was applied. Hyperthermia proved to be the most beneficial method of pain treatment.

Hyperthermia results in analgesia, enhanced tissue perfusion due to vasodilatation, relaxation of skeletal muscles, and reduction of soft tissue tension. Beneficial effects of hyperthermia were described in the treatment of exudative arthritis. Hyperthermia enabled a reduction of pain complaints, and stabilisation of prostaglandin E2 concentration and of leucocyte count in the exudate. The beneficial effects of hyperthermia persisted for six weeks after the last hyperthermia therapeutic procedure [21].

Zauner et al. [28] support the concept of systemic immunological effects of moderate whole-body hyperthermia in patients with AS. In a pilot study the increase of expression of toll-like receptor 4 (TLR-4), interleukin 10 (IL-10), and heat shock protein $\beta$ (HSPB1) was observed. Also, an increase of natural killer cells CD4+ and CD8+ $T$ lymphocytes was observed during hyperthermia, while no changes were observed in cytokine concentrations.

In a preliminary report by Agrawal [29], in all patients with RA a significant improvement was seen at the end of treatment and post-treatment. Patients received treatment that included whole-body hyperthermia, ozone major autohemotherapy, intravenous vitamin C, and individual nutrition counselling for four weeks. Pain and stiffness were reduced by over $40 \%$, while fatigue was reduced by nearly $60 \%$, for patients with RA. However, the study was limited to only eight patients, and hyperthermia was not the only method used in patients [29].

Oosterveld et al. [30], analysing physiological responses to whole-body hyperthermia in patients with RA and AS compared to healthy subjects, showed that this method has statistically significant positive direct effects upon pain and stiffness in RA and in AS patients, and in both diseases patients did not respond differentially from age- and gender-matched healthy controls.

Similarly as in the chemotherapy of tumours, systemic hyperthermia can increase the effectiveness of cytostatics used in the therapy of rheumatic diseases. Systemic hyperthermia is characterised by different actions in var- 
ious phases of the cell cycle, in which cell death due to hyperthermia takes place at various paces, depending on the phase of the cell cycle. The cells in M and S1 phases of the cell cycle are most sensitive to the effect of hyperthermia. The cells in G1 phase of the cell cycle are potentially resistant to the effects of thermal energy; therefore, in microscopic examination no traces are seen of hyperthermia-induced damage to those cells.

Generally, hyperthermia is well tolerated. However, there are some contraindications such as: existing or impending thrombosis, advanced destructive inflammation of internal organs such as progressive pulmonary tuberculosis, acute or progressive chronic hepatitis and nephritis, liver cirrhosis, cardiac insufficiency, and severe arrhythmias, advanced coronary atherosclerosis, and pronounced dehydration [31].

\section{Conclusions}

Hyperthermia may play an important role as an adjunctive treatment in the therapy of fibromyalgia and ankylosing spondylitis.

Beneficial clinical effects of hyperthermia are observed in the therapy of fibromyalgia and ankylosing spondylitis with the use of systemic hyperthermia at temperatures below $41^{\circ} \mathrm{C}$.

The determination of the role of hyperthermia in diseases other than fibromyalgia and ankylosing spondylitis requires an assessment in prospective randomised clinical trials.

The author declares no conflict of interest.

\section{References}

1. Neymann CA, Osborne SI. Artificial fever produced by high frequency currents: preliminary report. Illinois Med J 1929; 56: 199-203.

2. Short CL, Bauer W. Treatment of rheumatoid arthritis with fever induced by diathermy. A follow-up study. JAMA 1935; 104: 2165-2168.

3. Pallazzi M, Maluta S, Dall'Oglio S, et al. The role of hyperthermia in the battle against cancer. Tumori 2010; 96: 902-910.

4. Van der Zee J. Heating the patient: a promising approach? Ann Oncol 2002; 13: 1173-1184.

5. Hildebrandt B, Wust P, Ahlers O, et al. The cellular and molecular basis of hyperthermia. Crit Rev Oncol Hematol 2002; 43: 33-56.

6. Tarner IH, Múller-Ladner U, Uhlemann C, Lange U. The effect of mild whole-body hyperthermia on systemic levels of TNF-alpha, IL-1beta, and IL-6 in patients with ankylosing spondylitis. Clin Rheumatol 2009; 28: 397-402.

7. Schmidt KL, Simon E. Thermotherapy of pain, trauma and inflammatory and degenerative rheumatic diseases. In: Thermotherapy for neoplasia, inflammation and pain, Kosaka $M$
Sugahara T, Schmidt Kl et al. (eds.). Tokyo, Berlin, Heidelberg 2001: 527-539.

8. Schmidt KL. Aktuelle Aspekte der Balneotherapie rheumatischer Erkrankungen. In: Balneologie, Medizinische Klimatologie bei rheumatischen Erkrankungen, Karagülle MZ, Gutenbrunner C, Karagülle O (eds.). ISMH Verlag, Törpin 2003: 49-58.

9. Akyurekli D, Gerig LH, Raaphorst GP. Changes in muscle blood flow distribution during hyperthermia. Int I Hyperthermia 1997; 13: 481-496.

10. Brosseau L, Yonge KA, Robinson V, et al. Thermotherapy for treatment of osteoarthritis. Cochrane Database Syst Rev 2003; 4: CD004522.

11. Giombini A, Di Cesare A, Safran MR, et al. Short term effectiveness hyperthermia for supraspinatus tendinopathy in athletes. A short term randomized controlled study. Am J Sport Med 2007; 34: 1247-1253.

12. Giombini A, Giovannini V, Di Cesare A, et al. Hyperthermia induced by microwave diathermy in the management of muscle tendon and injuries. Br Med Bull 2007; 83: 379-396.

13. Leon SA, Sabell SO, Arastu HH, et al. Effects of hyperthermia on bone. II.Heating of bone in vivo and stimulation of bone growth. Int J Hyperthermia 1993; 9: 77-87.

14. Markovic M. Short term hyperthermia prevents activation of proinflammatory genes in type $B$ synoviocytes by blocking the activation of the transcription factor NF-KB. EJIFCC 2007; 18: 121-125.

15. Stuhlmeier KM. Short term hyperthermia prevents the activation of mitogen-activated protein kinase p38. Exp Gerontol 2009; 44: 406-412

16. Huang YH, Haegerstrand A, Frostegard J. Effects of in vitro hyperthermia on proliferative responses and lymphocyte activity. Clin Exp Immunol 1996; 103: 61-66.

17. Kappel M, Diamant M, Hansen MB, et al. Effects of in vitro hyperthermia on the proliferative response of blood mononuclear subsets and detection of interleukin 1 and 6, tumor necrosis factor alpha and interferon-gamma. Immunology 1991; 73: 304-308.

18. Kappel M, Stadeager C, Tvede N, et al. Effects of in vivo hyperthermia on natural killer cell activity, in vitro proliferative responses and blood mononuclear cell subpopulations. Clin Exp Immunol 1991; 84: 175-180.

19. Sukenik S, Flusser D, Abu-Shakra M. The role of spa therapy in various rheumatic diseases. Rheum Dis North Am 1999; 25 : 883-897.

20. Lehmann JF, Warren CG, Scham SM. Therapeutic heat and cold. Clin Orthop 1974; 99: 207-245.

21. Weinberger A, Fadilah R, Lev A, et al. Treatment of articular effusions with local deep microwave hyperthermia. Clin Rheumatol 1989; 8: 461-466

22. Otremski I, Erling G, Cohen Z, et al. The effect of hyperthermia $\left(42.5^{\circ} \mathrm{C}\right)$ on zymosan-induced synovitis of the knee. $\mathrm{Br} J \mathrm{Rheu}-$ matol 1994; 33: 721-723.

23. Brenner M, Braun C, Oster M, et al. Thermal signature analysis as a novel method for evaluating inflammatory arthritis activity. Ann Rheum Dis 2006; 65: 306-311.

24. Xiao J, Yang Y, He ZZ, Liu J. Investigation on three-dimensional temperature field of human knee considering anatomical structure. Intern J Heat Mass Transf 2011; 54: 1851-1860. 
25.Schleenbecker H, Schmidt KL. Zur Wirkung einer iterativen milden Ganzkŏrper-Hypertermie auf den Fibromyalgie Schmerz. Phys Rehab Kur Med 1998; 8: 113-117.

26. Brockow T, Wagner A, Franke A, et al. A randomized controlled trial on the effectiveness of mild water-filtered near infrared whole-body hyperthermia as an adjunct to a standard multimodal rehabilitation in the treatment of fibromyalgia. Clin J Pain 2007; 23: 67-75.

27. Chrubasik S, Junck H, Zappe HA, et al. A survey on pain complaints and health care utilization in a German population. Eur J Anaesthesiol 1998; 15: 397-408.

28. Zauner D, Quehenberger F, Hermann J, et al. Whole body hyperthermia treatment increases interleukin 10 and toll-like receptor 4 expression in patients with ankylosing spondylitis: a pilot study. Int J Hyperthermia 2014; 30: 393-401.
29. Agrawal S. Effects of moderate whole-body hiperthermia and complementary medicine in the treatment of rheumatoid arthritis: a preliminary study. Oncothermia J 2018; 22: 8-19.

30. Oosterveld FGJ, Koopman E, Scholtenhuis JO, et al. No adverse physiological response to infrared whole body hyperthermia in patients with rheumatoid arthritis and ankylosing spondylitis compared to healthy subjects. In: World Scientific and Engineering Academy and Society (ed.). Advances in biomedical research. University of Cambridge, February 23-25, 2010. WSEAS Press, 2010: 252-259.

31. Romeyke T, Scheuer HC, Stummer H. Fibromyalgia with severe forms of progression in a multidisciplinary therapy setting with emphasis on hyperthermia therapy - a prospective controlled study. Clin Interv Aging 2014; 10: 69-79. 